\title{
Ghd 7 is a negative regulator of zinc concentration in brown rice
}

\author{
Mufid Alam • Yingnanjun Chen • Pingbo Li • Guangming Lou • Hao Zhou • Lei Wang • \\ Rongjia Liu • Pingli Chen • Yin Zhou • Guanjun Gao • Dewei Tai • Xiaozhong Zhang • \\ Yuqing $\mathrm{He}$ (D)
}

Received: 4 September 2020 / Accepted: 26 November 2020 /Published online: 3 December 2020

(C) The Author(s) 2020

\begin{abstract}
Zinc ( $\mathrm{Zn})$ is an essential micronutrient for human, and improving $\mathrm{Zn}$ concentration in rice could be a simple and effective way to solve insufficient $\mathrm{Zn}$ uptake from daily diet. In this study, a recombinant inbred line (RIL) population was developed from a commercial hybrid combination Wandao153, and subjected to quantitative trait loci (QTL) detection for $\mathrm{Zn}$ concentration in brown rice and heading date. Five QTL for $\mathrm{Zn}$ concentration and six for heading date were detected across 2 years, among which two QTL for Zn concentration and two for heading date were co-located on chromosome 7 and 8, respectively. The two colocated QTL on chromosome 7, $q \mathrm{Zn} 7$ and $q H d 7$, were
\end{abstract}

\footnotetext{
e-mail: yqhe@mail.hzau.edu.cn

M. Alam

e-mail: mufid.agribhu@gmail.com

Y. Chen

e-mail: cynjzy@icloud.com

P. Li

e-mail: lipingboxwmr@126.com

G. Lou

e-mail: moliqiancha@163.com
}

M. Alam • Y. Chen · P. Li · G. Lou • H. Zhou • L. Wang •

R. Liu $\cdot$ P. Chen $\cdot$ Y. Zhou $\cdot$ G. Gao $\cdot$ Y. He $(\bowtie)$

National Key Laboratory of Crop Genetic Improvement and

National Center of Crop Molecular Breeding, Huazhong

Agricultural University, Wuhan 430070 Hubei, China

H. Zhou

e-mail: zhouhao@webmail.hzau.edu.cn likely to be $G h d 7$, a major gene for heading date and yield potential in rice. A combination of $\mathrm{Zn}$ concentration analysis and haplotype analysis of three pairs of genetic materials for $G h d 7$ revealed that it is a negative regulator of $\mathrm{Zn}$ concentration in brown rice. The other two co-located QTL on chromosome 8, $q \mathrm{Zn} 8$ and $q H d 8$, were likely to be $G h d 8 / D T H 8$, another major gene for heading date and yield potential in rice. These results could be of great use in genetic improvement of $\mathrm{Zn}$ concentration in brown rice.

Keywords Oryza sativa $\cdot$ Zinc concentration $\cdot$ Heading date $\cdot$ Quantitative trait loci · Ghd7 · Ghd8
L. Wang
e-mail: 5685349@qq.com
R. Liu
e-mail: 15527897208@sina.cn
P. Chen
e-mail: pingzi0826@163.com
Y. Zhou
e-mail: 13164651639@163.com
G. Gao
e-mail: gaojun8199@webmail.hzau.edu.cn
D. Tai $\cdot X$. Zhang $(\bowtie)$
Anhui Academy of Agricultural Sciences, Hefei 230001, China e-mail: xzzhang5700@sina.com
D. Tai
e-mail: dwtai5700@sina.com 


\section{Introduction}

$\mathrm{Zn}$ is an essential micronutrient for human, and $\mathrm{Zn}$ deficiency accumulates principle cause of malnutrition. Insufficient $\mathrm{Zn}$ uptake stimulates stunting growth, attenuated immunity power, diarrhea, lesions developed on eyes and skin, reduced wound healing, mental sickness, etc. (Gibson 2012). Rice (Oryza sativa L.) is a pioneer cereal crop being globally produced and a staple food feeding 3.5 billion of people, especially for Asian countries. Huge variation in $\mathrm{Zn}$ concentration in rice grain has been observed in different accessions (Roy and Sharma 2014). Therefore, development of rice cultivars displaying high $\mathrm{Zn}$ concentration in rice grain could be an effective way to reduce $\mathrm{Zn}$ malnutrition.

Genetic improvement of $\mathrm{Zn}$ concentration in rice grain through traditional breeding approach is difficult, as $\mathrm{Zn}$ concentration is a complex quantitative trait and controlled by many quantitative trait loci (QTL). Mapping of QTL for Zn concentration has been potentially achieved utilizing different genetic populations, including $F_{2}$ population (Kumar et al. 2014), recombinant inbred line (RIL) population (Anuradha et al. 2012; Dong et al. 2006; Surekha et al. 2012; Zhang et al. 2014), doubled haploid (DH) population (Stangoulis et al. 2007), and introgression line (IL) population (Xu et al. 2016). Huge numbers of QTL for Zn concentration have been discovered in various genetic backgrounds (Graham et al. 1999; Huang et al. 2012; Jeong et al. 2020; Lee et al. 2014; Lu et al. 2008; Stangoulis et al. 2007; Swamy et al. 2016; Zhang et al. 2014; Zhong et al. 2011). Among that, many candidate genes have been put forward, but no functional natural variation has been cloned. Therefore, more work is needed to clone functional genes for $\mathrm{Zn}$ concentration and to elucidate the regulating mechanism underlying variation in $\mathrm{Zn}$ concentration.

Heading date is one of the most important agronomic traits in rice, which determines the regional adaptation and yield potential of various rice accessions (Gao et al. 2014; Zhang et al. 2015). Up to now, dozens of QTL controlling heading date have been cloned in rice, and a clear gene regulatory network of heading date has been achieved (Hori et al. 2016; Sun et al. 2014). Increasing evidences indicate that genes controlling heading date play roles in many other biological processes. For example, Ghd7, an important regulator of heading date and yield potential in rice, has been reported to be involved in hormone metabolism, and biotic and abiotic stresses (Weng et al. 2014; Xue et al. 2008). Ghd7 has also been proved to be a negative regulator of nitrogen concentration in shoots at heading stage, straw, and brown rice (Yang et al. 2018). In addition, the concentration of different micronutrients is affected by heading date (Yang et al. 2018). Therefore, $\mathrm{Zn}$ concentration is likely to be influenced by heading date and regulated by related genes.

Population genotyping is a key concern of QTL mapping in genetic studies. In the past decade, the development of next-generation sequencing technologies has enabled re-sequencing of the rice genome accessible to common researchers, and allows detection of large numbers of polymorphic loci among different rice accessions, such as insert/deletion (InDel) and single nucleotide polymorphism (SNP) (Huang et al. 2013; Wang et al. 2018; Zhao et al. 2015). Thus, molecular markers obtained from re-sequencing have been widely adopted in population genotyping (Huang et al. 2009; Xie et al. 2010). In order to reduce the cost and improve accuracy of population genotyping, some reducedrepresentation sequencing technologies have been developed, such as restriction-site-associated DNA sequencing (RAD) and genotyping-by-sequencing (GBS) (Scheben et al. 2017). Among that, double digest RAD (ddRAD) that could control the number of final markers by selecting different restriction enzyme combinations has been widely applied in population genotyping (Chen et al. 2013; Wu et al. 2016; Zhou et al. 2014).

In this study, a RIL population was developed from the commercial two-line hybrid combination "Wandao 153" and population genotyping was conducted using the ddRAD technology. Zn concentration in rice brown grain and heading date of the RIL population were measured and related QTL were detected in 2 years. Among that, two major QTL, $q Z n 7$ and $q H d 7$, were colocated to the same interval on chromosome 7 , which were likely to be the major gene for heading date and yield in rice, Ghd7. Then, the genetic effect of Ghd7 on $\mathrm{Zn}$ concentration was evaluated in three pairs of genetic materials for Ghd7. Finally, the Ghd7 haplotype was analyzed for each rice accession used in this study.

\section{Materials and methods}

Genetic materials and field experiments

In this study, seven rice accessions were used to construct genetic materials, namely, 1892S, RH003, Jin 
23B, CR071, Zhenshan 97B (ZS97), Nanyangzhan (NYZ), and Minghui 63 (MH63). Among that, 1892S and RH003 are the parents of Wandao 153, a leading medium indica two-line hybrid rice combination, and ZS97 and MH63 are the parents of Shanyou 63, a leading indica three-line hybrid rice combination (http://www.ricedata.cn/variety/). Jin23B is a superior indica three-line maintainer line. CR071 is an indica breeding line with unknown origin. NYZ is a japonica accession showing large grain and red brown rice.

A RIL population consisting of 189 lines was derived from a cross between $1892 \mathrm{~S}$ and RH003, followed by a series of self-crosses using the single-seed decent method (Supplementary Fig. 1). The $F_{6}$ and $F_{7}$ generations were planted in year 2016 and 2017, respectively. Twelve plants per line were planted in a row, and all the lines were planted in a completely randomized design.

Two pairs of NILs for Ghd7 were developed by backcrossing the donor with the recurrent parent for four times, followed by a self-cross. One is NIL (CR071) and NIL (Jin23B), with CR071 and Jin23B being the donor and recurrent parent, respectively. The other is NIL (NYZ) and NIL (ZS97), with NYZ and ZS97 being the donor and recurrent parent, respectively. These NILs were planted in year 2018, with twelve plants per NIL in a row. Genetic complementary (CM) materials for Ghd7, CM+ and CM-, were constructed by introducing the Ghd7 allele from MH63 into the background of ZS97, which were kindly provided by Dr. Lei Wang. The CM materials were planted in year 2019, with twelve plants per line in a row.

All materials mentioned above were sowed in the seed bed on 15th of May and about 25 days old seedlings were transplanted in a row with $16.5 \mathrm{~cm}$ between pants and $26.4 \mathrm{~cm}$ between rows, at the experimental farm of Huazhong Agricultural University in Wuhan, Hubei. Field management followed standard agricultural practice.

Evaluation of heading date

The heading date of each line in the RIL population and the two parents was determined as described in Zhang et al. (2015).

Seeds harvesting and processing, and measurement of zinc concentration

Mixed seeds of three randomly selected plants from each line of the RIL population and seeds of each plant from NILs and CM lines of Ghd7 were harvested. Harvested seeds were further air-dried and stored at room temperature for at least 3 months. About $5 \mathrm{~g}$ of rice grains of each sample were dehulled using rice huller JLGJ4.5 (Taizhou Grain Instrument Factory, China), and then were dried in hot air oven at $80{ }^{\circ} \mathrm{C}$ for 2 days.

A total of $0.2 \mathrm{~g}$ of brown rice was weighted for each sample, followed by digestion with $65 \%$ nitric acid and $30 \%$ hydrogen peroxide in a MARS6 microwave (CEM) at $220^{\circ} \mathrm{C}$ for $45 \mathrm{~min}$. Next, samples were diluted into $40 \mathrm{ml}$ test tube, and the concentration of zinc was determined through atomic absorption spectrometry (AAS-Agilent 200 series, USA). Each sample was repeatedly measured for three times, and the mean value was treated as the zinc concentration of each sample.

Population genotyping, linkage map construction, and QTL analysis

High-quality genomic DNA was extracted from rice leaves of each line of the $\mathrm{F}_{7}$ generation and parents, and was subjected to double-digest restriction-associated DNA sequencing (ddRADseq) (Wu et al. 2016). A total of 39,379 SNP or insert/deletion (InDel) markers were identified and used to perform genotyping of the RIL population. Among that, a marker was selected to represent co-segregating markers, and finally 1550 markers were used to construct linkage maps.

The R package "onemap" was used to calculate genetic distances between neighboring markers and to construct linkage map of the RIL population. The software "WinQTLCart2.5" was used to perform QTL analysis using the composite interval mapping method with logarithm of odds (LOD) values over 2.5 (Silva et al. 2012).

Sequence analysis of $G h d 7$

Using the genome sequence of Nipponbare (NIP) and MH63 as the reference, 3 pairs of primers were designed to amplify and sequence the genomic region of Ghd7. Primers were listed in the Supplementary Table 1. Sequence alignment was performed using the software MEGA7 (Kumar et al. 2016), and the diagram of gene structure and sequence variation was charted using the software IBS1.0 (Liu et al. 2015). 
Statistical analysis

Correlation analysis of all traits of the RIL population and Student's $t$ test that was used to compare mean values of different genotypes were computed using the data analysis module in Microsoft Office Excel 2016.

\section{Results}

Phenotypic variation in the RIL population

Averaged across 2 years, the $\mathrm{Zn}$ concentration of RH003 was $15.82 \mathrm{mg} / \mathrm{kg}$ and the heading date was 103 days (Fig. 1). 1892S is a thermo-sensitive male sterile line, and cannot produce seeds in the normal planting season in Wuhan. Therefore, the $\mathrm{Zn}$ concentration of $1892 \mathrm{~S}$ was not provided, and its heading date was 83 days. For the RIL population, the $\mathrm{Zn}$ concentration appeared to follow normal distribution in both years, ranging from 5.58 to $26.22 \mathrm{mg} / \mathrm{kg}$ in year 2016 and from 10.78 to $23.84 \mathrm{mg} / \mathrm{kg}$ in year 2017 (Fig. 1a). In contrast, the heading date displayed continuous distribution in both years, ranging from 71 to 114 days in year 2016 and from 67 to 106 days in year 2017 (Fig. 1b).

The correlation coefficient of $\mathrm{Zn}$ concentration between the 2 years was far lower than that of heading date (Table 1). Significant negative correlation was observed between $\mathrm{Zn}$ concentration and heading date in each year, with a value of -0.592 in year 2016 and -0.305 in year 2017.

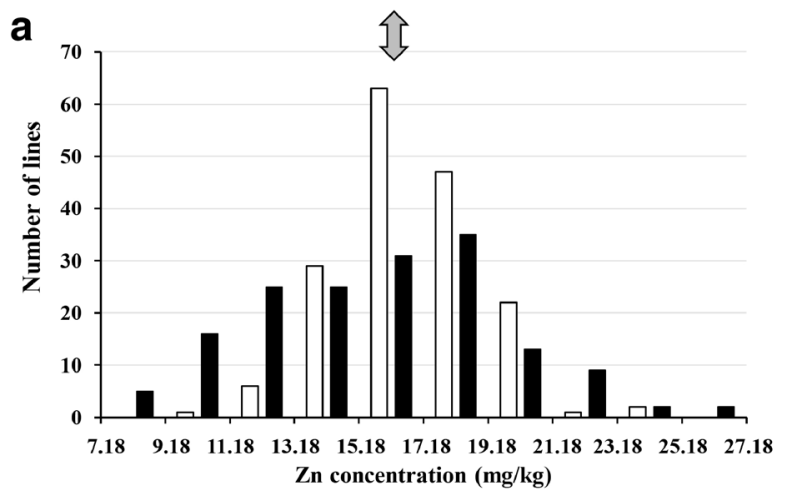

2017
Identified QTL for Zn concentration and heading date

In total, five QTL for Zn concentration and six QTL for heading date were identified in the RIL population in 2 years (Fig. 2a and Table 2). The phenotypic variation contributed by each QTL ranged from 3.08 to $37.52 \%$ (Table 2). Among the five QTL for Zn concentration, $q Z n 7$ was repeatedly detected in 2 years, and was located in the interval 5.35-18.11 Mb of chromosome 7 (Fig. $2 b)$. The allele from $1892 \mathrm{~S}$ increased $\mathrm{Zn}$ concentration by $0.71 \mathrm{mg} / \mathrm{kg}$ in 2017 and $1.83 \mathrm{mg} / \mathrm{kg}$ in 2016 . The remaining four QTL were only detected in 1 year, and all increasing alleles were from $1892 \mathrm{~S}$, except for that of $q Z n 8$.

Among the six QTL for heading date, $q H d 7$ and $q H d 8$ were repeatedly detected in 2 years. $q H d 7$ was located in the interval 5.35-18.11 Mb of chromosome 7, and contributed $37.52 \%$ and $32.72 \%$ of phenotypic variation in year 2016 and 2017, respectively, with the increasing allele from $\mathrm{RH} 003$. $q H d 8$ was located in the interval 3.70-8.25 Mb of chromosome 8, and contributed $18.13 \%$ and $17.61 \%$ of phenotypic variation in year 2016 and 2017, respectively, with the increasing allele from $1892 \mathrm{~S}$. The remaining showed minor effect on heading date, and were only detected in 1 year.

Zn concentration of NILs and CM lines for Ghd7

The co-localization of $q Z n 7$ and $q H d 7$ indicated that the same gene may regulate $\mathrm{Zn}$ concentration and heading date simultaneously. In the region of $q H d 7, G h d 7$, a major gene for heading date and yield, is located, and

b

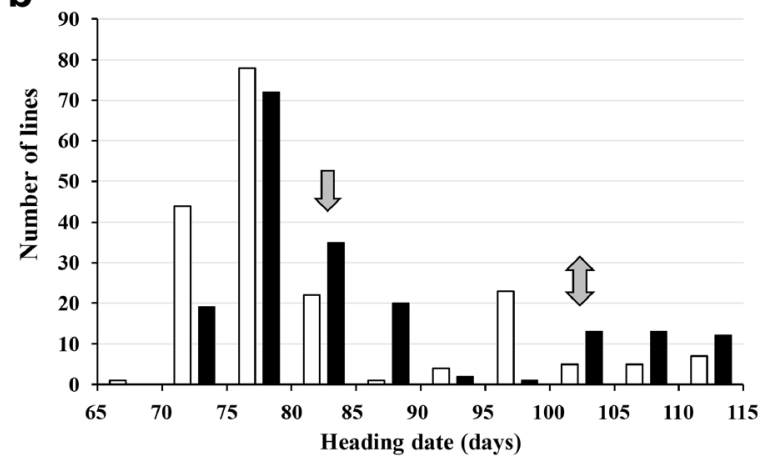

约 1892S 仓 RHO03

Fig. 1 Distribution of zinc concentration in brown rice (a) and heading date (b) of the WD153 population in year 2016 and 2017. The single arrow and double-headed arrows indicate the average values of $1892 \mathrm{~S}$ and RH003, respectively 
Table 1 Correlation coefficient between zinc concentration and heading date of the WD153 RIL population in year 2017 and 2016

\begin{tabular}{lrlll}
\hline & Zn17 & Zn16 & Hd17 & Hd16 \\
\hline Zn17 & & & \\
Zn16 & $0.257 * * *$ & & \\
Hd17 & $-0.305 * * *$ & $-0.611 * * *$ & \\
Hd16 & $-0.260 * * *$ & $-0.592 * * *$ & $0.898 * * *$ & \\
\hline
\end{tabular}

Note: Zn17, zinc concentration in year 2017. Zn16, zinc concentration in year 2016. Hd17, heading date in year 2017. Hd16, heading date in year 2016. *** Significant at $P<0.001$

thus likely to be the candidate gene. Then, the $\mathrm{Zn}$ concentration of two pairs of NILs and a pair of CM lines for $G h d 7$ was evaluated.

In the background of Jin23B, the $\mathrm{Zn}$ concentration of NIL (CR071) was $9.53 \mathrm{mg} / \mathrm{kg}$ lower than that of NIL (Jin23B) (Fig. 3a). In the background of ZS97, the Zn concentration of NIL (NYZ) was $5.40 \mathrm{mg} / \mathrm{kg}$ lower than that of NIL (ZS97) (Fig. 3b). In the background of $\mathrm{ZS} 97$, the $\mathrm{Zn}$ concentration of $\mathrm{CM}+$, the positive plant carrying Ghd7 allele from MH63, was $3.76 \mathrm{mg} / \mathrm{kg}$ lower than that of CM- (Fig. 3c).

\section{Haplotype analysis of $G h d 7$}

The genetic effect of Ghd7 on Zn concentration was different in different genetic materials (Fig. 3), which may be caused by different Ghd 7 haplotypes. Therefore, the Ghd7 alleles of seven rice accessions used in this a

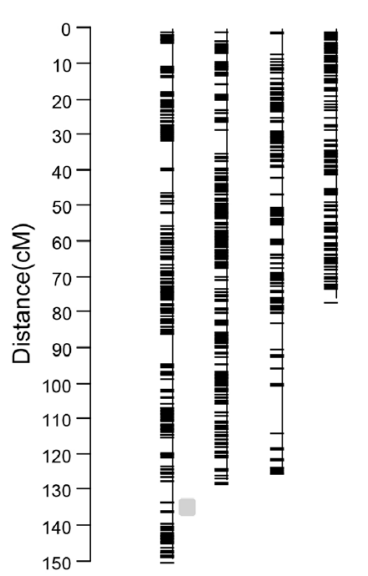

GeneticMap

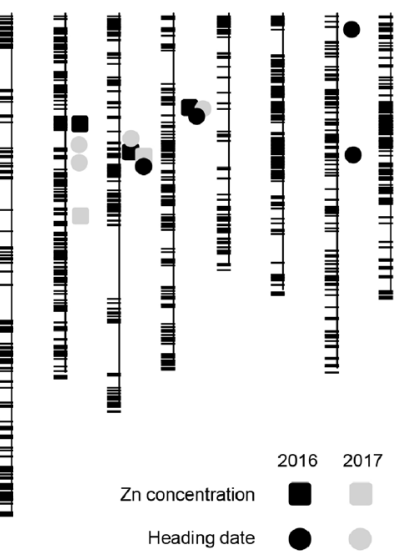

Fig. 2 QTL identified for Zn concentration and heading date from the WD153 population in year 2016 and 2017. a Distribution of putative QTL for Zn concentration and heading date on the linkage study were sequenced and compared. The Ghd7 region is deleted in 1892S, Jin23B, and ZS97, of which the allele was termed the type Hap9 reported by Zhang et al. (2015) (Fig. 4a). For the remaining four cultivars, 24 variations were identified in the coding region of $G h d 7$, including four SNPs on the first exon, three SNPs on the second exon, and seventeen SNPs in the intron (Fig. 4b). The allele of MH63 was termed Hap1, the allele of RH003 and CR071 was termed Hap2, and the allele of NYZ was termed Hap4, as reported by Zhang et al. (2015).

\section{Discussion}

Heading date is an important agronomic trait for rice, which not only determines yield potential but also affects many other aspects. In this study, a significant negative correlation between heading date and $\mathrm{Zn}$ concentration in brown rice was observed across 2 years in the RIL population, indicating that some genes may have effects on both the two traits (Table 1). QTL analysis revealed that two QTL for Zn concentration was co-located with two for heading date, which were distributed on chromosome 7 and 8 , respectively (Table 2). The co-located QTL on chromosome 7, $q \mathrm{Zn} 7$ and $q H d 7$, were repeatedly detected across 2 years, and were likely to be $G h d 7$ due to its large effect on heading date. Analysis of $\mathrm{Zn}$ concentration of three pairs of genetic materials further demonstrated that $G h d 7$ is a

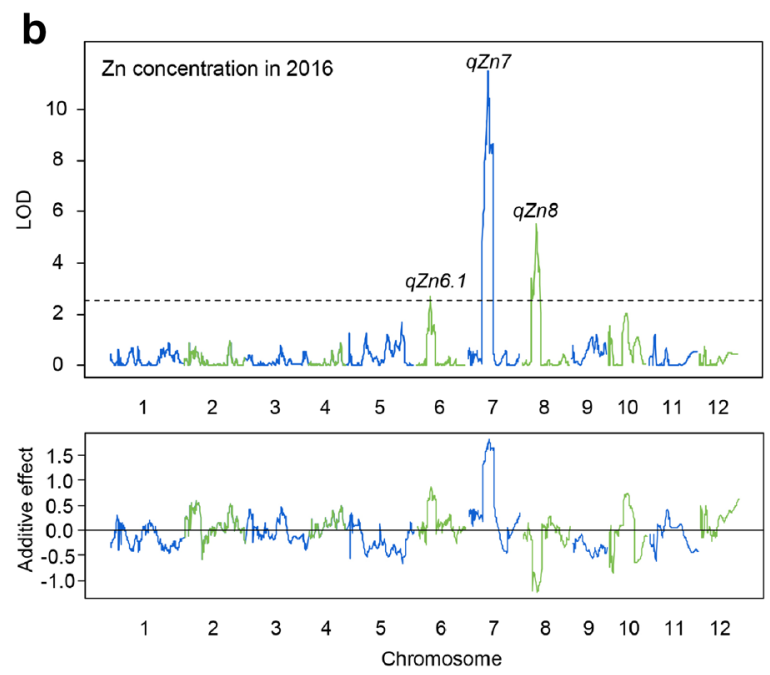

map. QTL for the two traits were marked by box and circle respectively. b QTL mapping result of $\mathrm{Zn}$ concentration in year 2016. The significance LOD threshold of QTL is 2.5 
Table 2 QTL for zinc concentration and heading date detected in the WD153 RIL population in year 2017 and 2016

\begin{tabular}{|c|c|c|c|c|c|c|c|c|c|c|}
\hline \multirow[t]{2}{*}{ Trait } & \multirow[t]{2}{*}{ QTL } & \multirow[t]{2}{*}{ Chrs } & \multicolumn{2}{|c|}{ Physical interval } & \multicolumn{3}{|l|}{2017} & \multicolumn{3}{|l|}{2016} \\
\hline & & & LB & $\mathrm{RB}$ & LOD & Add & $R^{2}(\%)$ & LOD & Add & $R^{2}(\%)$ \\
\hline \multirow[t]{5}{*}{$\mathrm{Zn}$} & $q Z n 1$ & 1 & $41,225,126$ & $42,415,524$ & 2.72 & 0.61 & 5.21 & & & \\
\hline & $q Z n 6.1$ & 6 & $5,330,965$ & $6,595,169$ & & & & 2.66 & 0.87 & 4.60 \\
\hline & $q Z n 6.2$ & 6 & $19,904,757$ & $21,770,585$ & 3.26 & 0.70 & 6.84 & & & \\
\hline & $q Z n 7$ & 7 & $5,357,882$ & $18,117,359$ & 3.50 & 0.71 & 6.66 & 11.23 & 1.83 & 20.93 \\
\hline & $q Z n 8$ & 8 & $3,704,503$ & $8,258,472$ & & & & 5.42 & -1.23 & 9.30 \\
\hline \multirow[t]{6}{*}{ HD } & qHd6.1 & 6 & $7,654,413$ & $9,678,412$ & 4.22 & -2.09 & 4.17 & & & \\
\hline & qHd6.2 & 6 & $11,662,994$ & $13,087,569$ & 3.13 & -1.79 & 3.08 & & & \\
\hline & $q H d 7$ & 7 & $5,357,882$ & $18,117,359$ & 21.55 & -5.78 & 32.72 & 28.32 & -7.44 & 37.52 \\
\hline & $q H d 8$ & 8 & $3,704,503$ & $8,258,472$ & 15.55 & 4.21 & 17.61 & 15.71 & 5.89 & 18.13 \\
\hline & $q H d 11.1$ & 11 & 44,787 & $1,117,097$ & & & & 3.92 & 2.38 & 3.76 \\
\hline & $q H d 11.2$ & 11 & $7,473,709$ & $9,009,364$ & & & & 3.69 & -2.37 & 3.61 \\
\hline
\end{tabular}

negative regulator of $\mathrm{Zn}$ concentration in brown rice (Fig. 3). The other co-located QTL on chromosome 8, $q Z n 8$ and $q H d 8$, were likely to be Ghd8/DTH8, another major gene for heading date and yield potential in rice (Wei et al. 2010; Yan et al. 2011). qZn8 was not detected in year 2017, which may be caused by the environment effect for that the genetic effect of $q Z n 7$ in year 2017 was far less than that in year 2016 (Table 2). Therefore, $\mathrm{Zn}$ concentration in brown rice is easily affected by environment, and manipulating unique alleles for heading date, such as Ghd7 and Ghd8/DTH8, would be an effective way to improve $\mathrm{Zn}$ concentration in brown rice.
Ghd7 encodes a transcription factor, and acts as a central regulator of growth, development, and stress response in rice (Weng et al. 2014). However, the effect of Ghd7 on grain components has never been explored, except that it is a negative regulator of nitrogen concentration in brown rice (Yang et al. 2018). In this study, Ghd7 was proved to be able to reduce $\mathrm{Zn}$ concentration (Fig. 3). It is not clear whether there is any relationship between the effect on nitrogen and $\mathrm{Zn}$ concentration by Ghd7, which awaits further studies. In addition, it was noted that the effect of $G h d 7$ on $\mathrm{Zn}$ concentration was varying in different genetic materials and environments. For example, the additive effect of hap2 of Ghd7 was
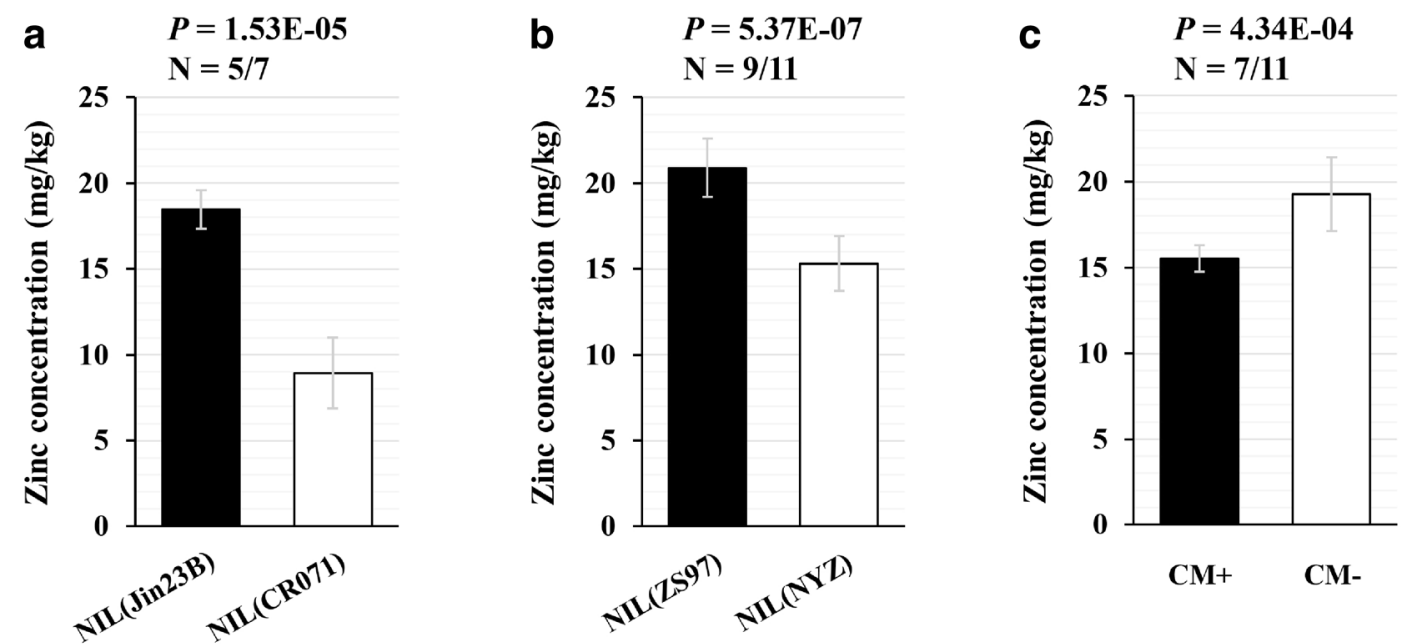

Fig. 3 The effects of Ghd7 on Zn concentration in NILs (a, b) and transgenic lines (c). NIL(Jin23B) and NIL(CR071) were developed using Jin23B as the recurrent parent, while NIL(ZS97) and NIL(NYZ) were developed using ZS97 as the recurrent parent 
a

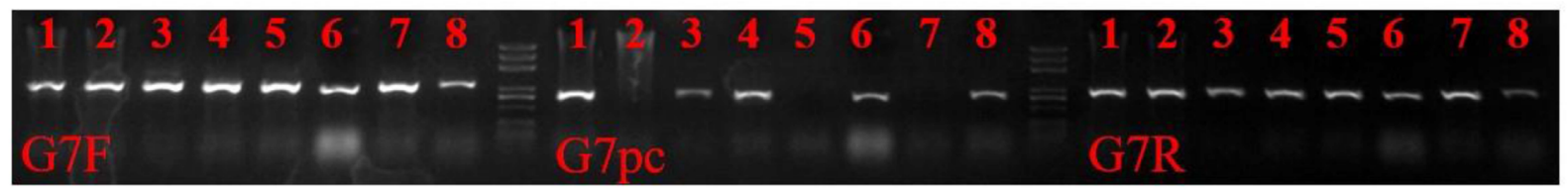

b

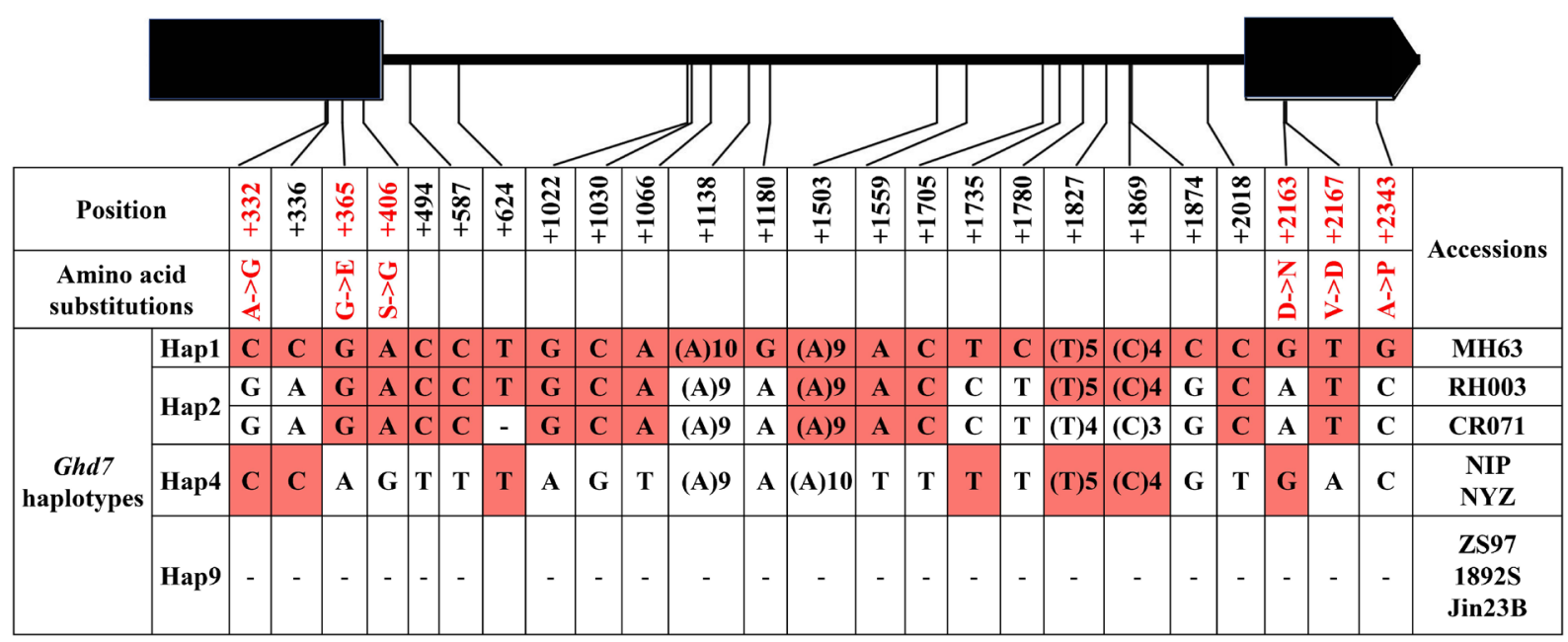

Fig. 4 Haplotype analysis of $G h d 7$ alleles in rice cultivars used in this study. a Ghd7 is deleted in some rice cultivars. G7F and G7R are primers that could amplify collinear regions flanking the insertion region containing $G h d 7$, respectively. G7pc is a primer amplifying a small genomic region of Ghd7. 1, RH003; 2, 1892S; 3, NIP; 4, CR071; 5, Jin23B; 6, NYZ; 7, ZS97; 8, MH63. Primer sequences of G7F, G7pc, and G7R are listed in supplementary

$0.70 \mathrm{mg} / \mathrm{kg}$ and $1.83 \mathrm{mg} / \mathrm{kg}$, respectively, in year 2017 and 2016 in the RIL population, but was about $5.00 \mathrm{mg} / \mathrm{kg}$ in year 2018 in the NILs with the background of J23B (Table 1, Fig. 3, Fig. 4). The different performance of hap2 of Ghd7 may be caused by environment factors in different years, or by different genetic backgrounds, the same as GL3.3 that can produce extra-long grains together with gs 3 but not with GS3 (Xia et al. 2018). Therefore, further work is needed to investigate the regulation of $\mathrm{Zn}$ concentration by Ghd7.

Supplementary Information The online version contains supplementary material available at https://doi.org/10.1007/s11032020-01193-x.

Funding This work was supported by grants from the National Program on R\&D of Transgenic Plants (2016ZX08009003-004) and the National Natural Science Foundation (91935303), and
Table 2. b Haplotypes of Ghd7 alleles. Black boxes above the table are exons of $G h d 7$ and the horizontal black line indicates the intron. MH63 genomic DNA sequence of Ghd7 was referenced to identify nucleotide polymorphism. Polymorphic nucleotides are indicated by white color. Amino acid substitutions marked in red are key variations differentiating different haplotypes (Zhang et al. 2015)

earmarked fund for Agriculture Research System (CARS-01-03) in China.

\section{Compliance with ethical standards}

Conflict of interest An enlisted author declares that they have no conflict of interest.

Open Access This article is licensed under a Creative Commons Attribution 4.0 International License, which permits use, sharing, adaptation, distribution and reproduction in any medium or format, as long as you give appropriate credit to the original author(s) and the source, provide a link to the Creative Commons licence, and indicate if changes were made. The images or other third party material in this article are included in the article's Creative Commons licence, unless indicated otherwise in a credit line to the material. If material is not included in the article's Creative Commons licence and your intended use is not permitted by statutory regulation or exceeds the permitted use, you will need to obtain 
permission directly from the copyright holder. To view a copy of this licence, visit http://creativecommons.org/licenses/by/4.0/.

\section{References}

Anuradha K, Agarwal S, Rao YV, Rao KV, Viraktamath BC, Sarla N (2012) Mapping QTLs and candidate genes for iron and zinc concentrations in unpolished rice of Madhukar×Swarna RILs. Gene 508(2):233-240. https://doi. org/10.1016/j.gene.2012.07.054

Chen X, Li XM, Zhang B, Xu J, Wu Z, Wang B, Li H, Younas M, Huang L, Luo Y, Wu J, Hu S, Liu K (2013) Detection and genotyping of restriction fragment associated polymorphisms in polyploid crops with a pseudo-reference sequence: a case study in allotetraploid Brassica napus. BMC Genomics 14: 346. https://doi.org/10.1186/1471-2164-14-346

Dong YJ, Ogawa T, Lin DZ, Koh HJ, Kamiunten H, Matsuo M, Cheng SH (2006) Molecular mapping of quantitative trait loci for zinc toxicity tolerance in rice seedling (Oryza sativa L.). Field Crop Res 95:420-425. https://doi.org/10.1016/j. fcr.2005.03.005

Gao H, Jin MN, Zheng XM, Chen J, Yuan D, Xin Y, Wang M, Huang D, Zhang Z, Zhou K, Sheng P, Ma J, Ma W, Deng H, Jiang L, Liu S, Wang H, Wu C, Yuan L, Wan J (2014) Days to heading 7, a major quantitative locus determining photoperiod sensitivity and regional adaptation in rice. P Natl Acad Sci USA 111(46):16337-16342. https://doi.org/10.1073 /pnas.1418204111

Gibson RS (2012) Zinc deficiency and human health: etiology, health consequences, and future solutions. Plant Soil 361: 291-299. https://doi.org/10.1007/s11104-012-1209-4

Graham R, Senadhira D, Beebe S, Iglesias C, Monasterio I (1999) Breeding for micronutrient density in edible portions of staple food crops: conventional approaches. Field Crop Res 60:57-80. https://doi.org/10.1016/S0378-4290(98)00133-6

Hori K, Matsubara K, Yano M (2016) Genetic control of flowering time in rice: integration of Mendelian genetics and genomics. Theor Appl Genet 129:2241-2252. https://doi.org/10.1007/s00122-016-2773-4

Huang XH, Feng Q, Qian Q, Zhao Q, Wang L, Wang A, Guan J, Fan D, Weng Q, Huang T, Dong G, Sang T, Han B (2009) High-throughput genotyping by whole-genome resequencing. Genome Res 19(6):1068-1076. https://doi. org/10.1101/gr.089516.108

Huang XH, Zhao Y, Wei XH, Li C, Wang A, Zhao Q, Li W, Guo Y, Deng L, Zhu C, Fan D, Lu Y, Weng Q, Liu K, Zhou T, Jing Y, Si L, Dong G, Huang T, Lu T, Feng Q, Qian Q, Li J, Han B (2012) Genome-wide association study of flowering time and grain yield traits in a worldwide collection of rice germplasm. Nat Genet 44:32-39. https://doi.org/10.1038 /ng.1018

Huang XH, Lu TT, Han B (2013) Resequencing rice genomes: an emerging new era of rice genomics. Trends Genet 29(4):225232. https://doi.org/10.1016/j.tig.2012.12.001

Jeong OY, Lee JH, Jeong EG, Chun A, Bombay M, Ancheta MB, Ahn SN (2020) Analysis of QTL responsible for grain iron and zinc content in doubled haploid lines of rice (Oryza sativa) derived from an intra-japonica cross. Plant Breed 139(2):344-355. https://doi.org/10.1111/pbr.12787

Kumar J, Jain S, Jain RK (2014) Linkage mapping for grain iron and zinc content in $F_{2}$ population derived from the cross between PAU201 and Palman 579 in Rice (Oryza sativa L.). Cereal Res Commun 42(3):389-400. https://doi. org/10.1556/crc.42.2014.3.3

Kumar S, Stecher G, Tamura K (2016) MEGA7: molecular evolutionary genetics analysis version 7.0 for bigger datasets. Mol Biol Evol 33(7):1870-1874. https://doi.org/10.1093 /molbev/msw054

Lee GH, Yun BW, Kim KM (2014) Analysis of QTLs associated with the rice quality related gene by double haploid populations. Int J Genomics 2014:781832. https://doi.org/10.1155 /2014/781832

Liu WZ, Xie YB, Ma JY, Luo X, Nie P, Zuo Z, Lahrmann U, Zhao Q, Zheng Y, Zhao Y, Xue Y, Ren J (2015) IBS: an illustrator for the presentation and visualization of biological sequences. Bioinformatics 31(20):3359-3361. https://doi.org/10.1093 /bioinformatics/btv362

Lu KY, Li LZ, Zheng XF, Zhang ZH, Mou TM, Hu ZL (2008) Quantitative trait loci controlling $\mathrm{Cu}, \mathrm{Ca}, \mathrm{Zn}, \mathrm{Mn}$ and $\mathrm{Fe}$ content in rice grains. J Genet 87:305-310. https://doi. org/10.1007/s12041-008-0049-8

Roy SC, Sharma BD (2014) Assessment of genetic diversity in rice [Oryza sativa $\mathrm{L}$.] germplasm based on agro-morphology traits and zinc-iron content for crop improvement. Physiol Mol Biol Plants 20:209-224. https://doi.org/10.1007 /s12298-014-0221-y

Scheben A, Batley J, Edwards D (2017) Genotyping-bysequencing approaches to characterize crop genomes: choosing the right tool for the right application. Plant Biotechnol J 15:149-161. https://doi.org/10.1111/pbi.12645

Silva LDCE, Wang SC, Zeng ZB (2012) Composite interval mapping and multiple interval mapping: procedures and guidelines for using Windows QTL Cartographer. In: Rifkin S (ed) Quantitative trait loci (QTL). Methods in molecular biology (methods and protocols), vol 871. Humana Press. https://doi.org/10.1007/978-1-61779-785-9_6

Stangoulis JCR, Huynh BL, Welch RM, Choi EY, Graham RD (2007) Quantitative trait loci for phytate in rice grain and their relationship with grain micronutrient content. Euphytica 154: 289-294. https://doi.org/10.1007/s10681-006-9211-7

Sun CH, Chen D, Fang J, Wang PR, Deng XJ, Chu CC (2014) Understanding the genetic and epigenetic architecture in complex network of rice flowering pathways. Protein Cell 5:889-898. https://doi.org/10.1007/s13238-014-0068-6

Surekha A, Vgn TV, Anuradha K, Mangrauthia S, Kumar N, Neelamraju S (2012) Expression patterns of QTL based and other candidate genes in Madhukar x Swarna RILs with contrasting levels of iron and zinc in unpolished rice grains. Gene 546(2):430-436. https://doi.org/10.1016/j. gene.2014.05.069

Swamy BPM, Rahman MA, Inabangan-Asilo MA, Amparado A, Manito C, Chadha-Mohanty P, Reinke R, Slamet-Loedin IH (2016) Advances in breeding for high grain zinc in rice. Rice 9:49. https://doi.org/10.1186/s12284-016-0122-5

Wang WS, Mauleon R, Hu ZQ, Chebotarov D, Tai S, Wu Z, Li M, Zheng T, Fuentes RR, Zhang F, Mansueto L, Copetti D, Sanciangco M, Palis KC, Xu J, Sun C, Fu B, Zhang H, Gao Y, Zhao X, Shen F, Cui X, Yu H, Li Z, Chen M, 
Detras J, Zhou Y, Zhang X, Zhao Y, Kudrna D, Wang C, Li R, Jia B, Lu J, He X, Dong Z, Xu J, Li Y, Wang M, Shi J, Li J, Zhang D, Lee S, Hu W, Poliakov A, Dubchak I, Ulat VJ, Borja FN, Mendoza JR, Ali J, Li J, Gao Q, Niu Y, Yue Z, Naredo MEB, Talag J, Wang X, Li J, Fang X, Yin Y, Glaszmann JC, Zhang J, Li J, Hamilton RS, Wing RA, Ruan J, Zhang G, Wei C, Alexandrov N, McNally KL, Li Z, Leung H (2018) Genomic variation in 3,010 diverse accessions of Asian cultivated rice. Nature 557:43-49. https://doi.org/10.1038/s41586-018-0063-9

Wei XJ, Xu JF, Guo HN, Jiang L, Chen S, Yu C, Zhou Z, Hu P, Zhai H, Wan J (2010) DTH8 suppresses flowering in rice, influencing plant height and yield potential simultaneously. Plant Physiol 153:1747-1758. https://doi.org/10.1104 /pp. 110.156943

Weng XY, Wang L, Wang J, Hu Y, Du H, Xu CG, Xing YZ, Li XH, Xiao JH, Zhang QF (2014) Grain number, plant height, and heading date 7 is a central regulator of growth, development, and stress response. Plant Physiol 164:735-747. https://doi.org/10.1104/pp.113.231308

Wu ZK, Wang B, Chen X, Wu JS, King GJ, Xiao YJ, Liu K (2016) Evaluation of linkage disequilibrium pattern and association study on seed oil content in Brassica napus using ddRAD sequencing. PLoS One 11(1):e0146383. https://doi. org/10.1371/journal.pone.0146383

Xia D, Zhou H, Liu RJ, Dan W, Li P, Wu B, Chen J, Wang L, Gao G, Zhang Q, He Y (2018) GL3.3, a novel QTL encoding a GSK3/SHAGGY-like kinase, epistatically interacts with GS3 to produce extra-long grains in rice. Mol Plant 11(5):754 756. https://doi.org/10.1016/j.molp.2018.03.006

Xie WB, Feng Q, Yu HH, Huang X, Zhao Q, Xing Y, Yu S, Han B, Zhang Q (2010) Parent-independent genotyping for constructing an ultrahigh-density linkage map based on population sequencing. P Natl Acad Sci USA 107(23):1057810583. https://doi.org/10.1073/pnas.1005931107

Xu Y, Li PC, Yang ZF, Xu CW (2016) Genetic mapping of quantitative trait loci in crops. Crop J 5(2):175-184. https://doi.org/10.1016/j.cj.2016.06.003

Xue WB, Xing YZ, Weng XY, Zhao Y, Tang W, Wang L, Zhou H, Yu S, Xu C, Li X, Zhang Q (2008) Natural variation in Ghd7 is an important regulator of heading date and yield potential in rice. Nat Genet 40(6):761-767. https://doi. org/10.1038/ng.143
Yan WH, Wang P, Chen HX, Zhou HJ, Li QP, Wang CR, Ding ZH, Zhang YS, Yu SB, Xing YZ, Zhang QF (2011) A major QTL, Ghd8, plays pleiotropic roles in regulating grain productivity, plant height, and heading date in rice. Mol Plant 4(2):319-330. https://doi.org/10.1093/mp/ssq070

Yang M, Lu K, Zhao FJ, Xie W, Ramakrishna P, Wang G, du Q, Liang L, Sun C, Zhao H, Zhang Z, Liu Z, Tian J, Huang XY, Wang W, Dong H, Hu J, Ming L, Xing Y, Wang G, Xiao J, Salt DE, Lian X (2018) Genome-wide association studies reveal the genetic basis of ionomic variation in rice. Plant Cell 30(11):2720-2740. https://doi.org/10.1105 /tpc. 18.00375

Zhang M, Pinson SRM, Tarpley L, Huang XY, Lahner B, Yakubova E, Baxter I, Guerinot ML, Salt DE (2014) Mapping and validation of quantitative trait loci associated with concentrations of 16 elements in unmilled rice grain. Theor Appl Genet 127:137-165. https://doi.org/10.1007 /s00122-013-2207-5

Zhang J, Zhou XC, Yan WH, Zhang Z, Lu L, Han Z, Zhao H, Liu H, Song P, Hu Y, Shen G, He Q, Guo S, Gao G, Wang G, Xing Y (2015) Combinations of the Ghd7, Ghd8 and Hdl genes largely define the ecogeographical adaptation and yield potential of cultivated rice. New Phytol 208(4):1056-1066. https://doi.org/10.1111/nph.13538

Zhao H, Yao W, Ouyang YD, Yang W, Wang G, Lian X, Xing Y, Chen L, Xie W (2015) RiceVarMap: a comprehensive database of rice genomic variations. Nucleic Acids Res 43: D1018-D1022. https://doi.org/10.1093/nar/gku894

Zhong M, Wang LQ, Yuan DJ, Luo LJ, Xu CG, He YQ (2011) Identification of QTL affecting protein and amino acid contents in rice. Rice Sci 18(3):187-195. https://doi.org/10.1016 /S1672-6308(11)60026-7

Zhou XJ, Xia YL, Ren XP, Chen Y, Huang L, Huang S, Liao B, Lei Y, Yan L, Jiang H (2014) Construction of a SNP-based genetic linkage map in cultivated peanut based on large scale marker development using next-generation double-digest restriction-site-associated DNA sequencing (ddRADseq). BMC Genomics 15(1):351. https://doi.org/10.1186/14712164-15-351

Publisher's note Springer Nature remains neutral with regard to jurisdictional claims in published maps and institutional affiliations. 